\title{
Imigrantes brasileiros no Québec: entre integração e mobilidade
}

\section{Resumo}

Em 1991, a província canadense do Québec conquistou autonomia para definir sua política migratória. O recrutamento e a seleção de imigrantes tornaram-se parte de um processo que, abrindo o Québec ao mundo, preocupou-se também em consolidar a especificidade local diante do Canadá, promovendo o chamado fait français. As políticas de integração os categorizaram como comunidades culturais e minorias visíveis. Definido o Brasil como área de imigração, o fluxo de brasileiros para o Québec aumentou 640\% no período 2006-2011 em relação ao quinquênio anterior. Os imigrantes brasileiros mostraram-se reservados diante da definição de uma minoria visível latino-americana e da adesão ao fait français. Ao mesmo tempo, procuraram elementos de aproximação cultural com a sociedade de acolhimento. A análise de percursos migratórios mostrou, ainda, que a obtenção da nacionalidade canadense é um forte componente na aquisição de um capital de mobilidade que, além de facilitar a integração, paradoxalmente, permite novas migrações.

Palavras-chave: Imigração brasileira. Processos de integração. Capital de mobilidade. Québec.

\footnotetext{
"Universidade Federal do Paraná (Brasil)

** Universidade Tecnológica Federal do Paraná (Brasil)
} 


\section{Brazilian immigrants in Québec: between integration and mobility}

\section{Abstract}

In 1991, Quebec became autonomous for defining its own migratory policies. Recruiting and selecting immigrants became part of a process that while opening Quebec to the world, was also concerned with building a French province image inside Canada through the fait français. However, integrating new immigrants also brought some challenges. The Quebec policies were meant to classify those new immigrants in the categories of cultural communities or visible minorities. After Latin America has been defined as a new area of immigration the flow of Brazilians increased $640 \%$ between 2006-2011.Data collected through interviews with Brazilian immigrants in Quebec showed that they felt rather reluctant regarding being defined as a Latin American visible minority and to join the fait français. At the same time, they tried to establish some elements that would put them closer to the local culture. The analyses of the migratory paths also showed that the demand for Canadian citizenship is a strong component of acquiring a capital of mobility, which promotes integration but, paradoxically, allows further migrations.

Key-words: Brazilian immigration. Integration processes. Capital of mobility. Québec.

\section{Introdução}

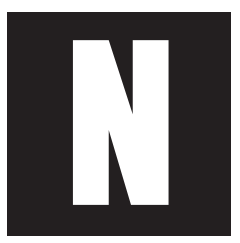

os anos que se seguiram à $2^{a}$ Guerra Mundial, o controle do processo migratório foi lentamente percebido pelos atores políticos do Québec como a ferramenta mais eficaz para assegurar a perenidade do denominado fait français ${ }^{1}$, ou seja, para afirmar sua autonomia política

\footnotetext{
${ }^{1}$ Fait français é uma expressão corrente no meio governamental e jornalístico do Québec. Sua utilização exprime o fato de que a língua francesa reflete a singularidade da história e da cultura quebequense.
} 
e cultural diante da federação canadense. Contudo, foi apenas no início dos anos 1990 que o Québec conquistou definitivamente o direito constitucional de controlar todo seu processo migratório, desde a seleção até a integração dos imigrantes. Desse momento em diante e como resposta à diminuição do fluxo migratório para a província, o Québec passou também a atrair imigrantes não francófonos em novas áreas de imigração. A abertura da província aos cidadãos de todo o mundo que, paradoxalmente, poderia colocar em risco a perenidade do fait français, foi então contrabalançada por um reforço no campo da integração dos novos imigrantes, através de ações que os classificaram como membros de comunidades culturais e de minorias visíveis.

A nova política de integração do governo do Québec revelar-se-ia, contudo, relativamente ambígua. Isso porque permaneceu ainda ligada ao reconhecimento, que os imigrantes deveriam fazer individualmente, da identidade cultural francesa como base da sociedade quebequense. Essa ambiguidade ficaria evidente no caso dos imigrantes brasileiros, quando o Brasil, a partir da abertura em 2008 de uma agência governamental, o Escritório de Imigração do Québec em São Paulo, foi transformado em nova área de imigração. As ações do Escritório produziram inegável aumento no número de brasileiros que se dirigiram à província. Produziram também consequências tanto do ponto de vista do reconhecimento legal quanto da integração dos mesmos. Os brasileiros foram classificados no interior da comunidade cultural latino-americana, mas até hoje não há estudos sobre isso. Como reagiram? Qual foi seu papel específico em relação ao fait français? Enfim, como perceberam seu percurso migratório e seu próprio processo de integração à sociedade quebequense, no plano particular, e à sociedade canadense no plano geral?

Para responder a estas perguntas, apresentamos inicialmente o papel das políticas imigratórias na busca por autonomia da província do Qué-

http://dx.doi.org/10.1590/15174522-017003911 
Sociologias, Porto Alegre, ano 17, no 39, mai/ago 2015, p. 248-275

bec. Em seguida, mostramos como a política de imigração do Québec descobriu a América Latina e como organizou sua política de seleção dos novos imigrantes, em especial os brasileiros. No terceiro momento, a partir de uma série de dados coletados junto aos brasileiros residentes hoje no Québec no ano de 2011, conforme explicamos mais tarde, mostramos como reagiram às políticas oficiais de integração e como descrevem seu percurso migratório. Como conclusão, apresentamos uma discussão sobre a forma como percebem o Québec (o fait français) e o Canadá em relação às suas próprias trajetórias e perspectivas futuras.

\section{A política imigratória do Québec: perenidade do fait français e integração}

O Québec é uma das dez províncias do Canadá e, junto com as províncias de Ontário, Nova Brunswick e Nova Escócia, pertence ao território canadense desde sua formação, em 1867. As outras sete províncias são: Alberta, Colúmbia Britânica, Manitoba, Terra Nova e Labrador, Ilha do Príncipe Eduardo e Saskatchewan. O Canadá é formado ainda por três territórios: Territórios do Noroeste, Nunavut, e Yukon. A província do Québec é a maior em extensão territorial e é a segunda mais habitada, ficando atrás de Ontário - onde fica a capital nacional, Ottawa - e à frente de Colúmbia Britânica. 
Sociologias, Porto Alegre, ano 17, no 39, mai/ago 2015, p. 248-275

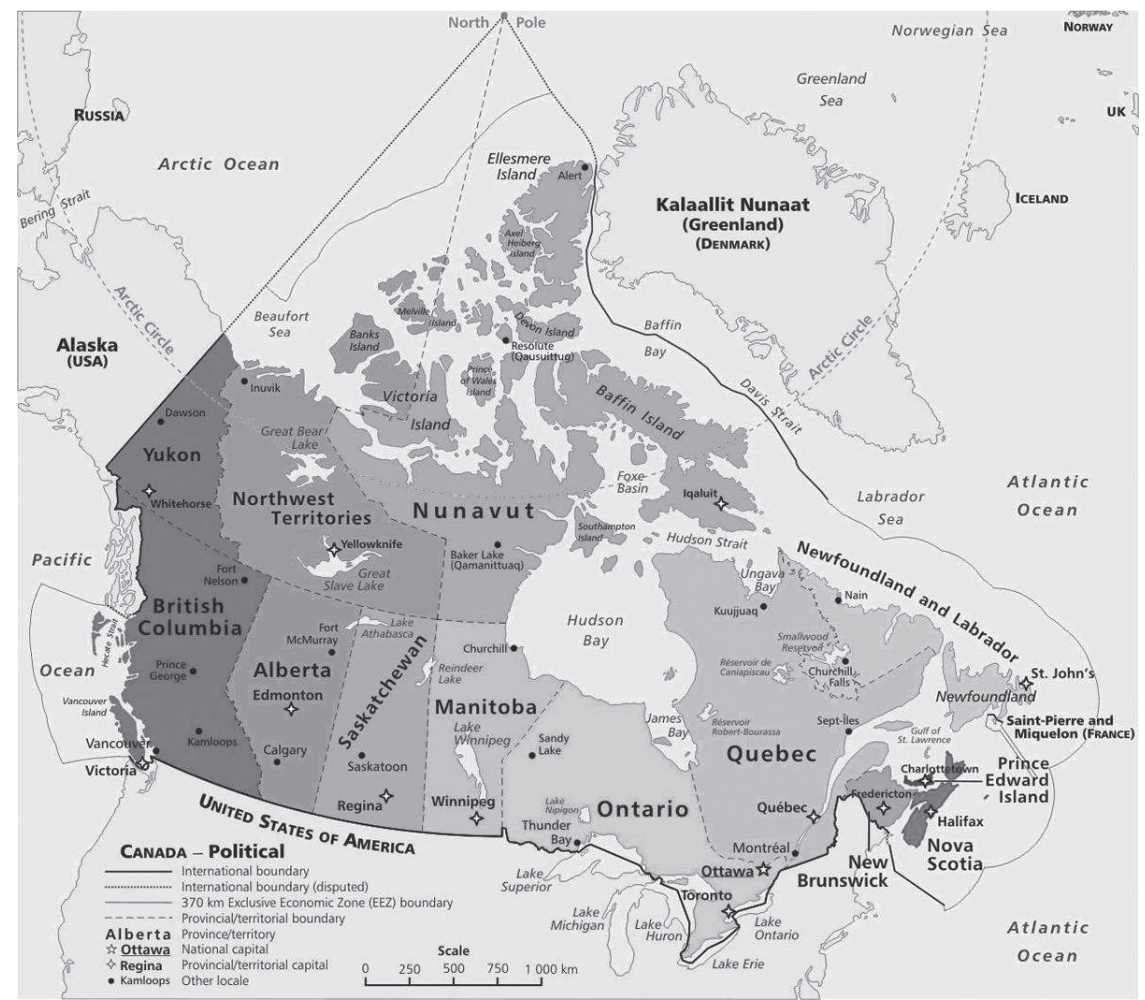

Figura 1. Mapa político do Canadá

Fonte: The Atlas of Canadá (2012). 
Sociologias, Porto Alegre, ano 17, no 39, mai/ago 2015, p. 248-275

O ano de 1945 marca definitivamente o início dos debates políticos sobre o tema da imigração entre a província francófona do Québec e o Canadá. Fontaine (1995) explica que, a partir de então, o termo Province du Québec foi gradualmente substituído pelos termos Le Québec ou L'Etat du Québec tanto no campo da política quanto nos meios de comunicação. Nos anos 1960, a denominada Révolution Tranquille ${ }^{2}$ possibilitou o surgimento de uma nova concepção de sociedade e de identidade nacional francófona no Québec, redefinindo o papel do Estado e criando novas estruturas burocráticas. Em 1965, é criado um serviço de imigração, inicialmente ligado ao Ministério da Educação. Esse serviço deu origem mais tarde, em 1968, ao Ministério da Imigração do Québec (MIQ). Latouche (1989) afirma que a nova estrutura burocrática tinha por foco a integração dos novos imigrantes à comunidade francófona, oferecendo-lhes inclusive cursos de francês. Lentamente, o imigrante, sem ter consciência disso, tornava-se o principal instrumento de uma política que, fundamentalmente preocupada com o decréscimo populacional e com a necessidade de dinamizar a economia local, pretendia consolidar a especificidade da província diante da federação.

Em 1978, o Estado do Canadá sanciona a chamada Lei de Imigração de 1976 através da qual as províncias podiam elaborar livremente suas próprias políticas de imigração, ao mesmo tempo em que obrigava o governo federal a consultá-las antes de estabelecer suas ações nessa matéria. Nesse mesmo ano de 1978, após vinte anos de negociações, foi firmado

${ }^{2}$ A chamada Revolução Tranquila foi um período de mudanças em diferentes áreas sociais, econômicas, culturais e políticas. Com a chegada do Parti libéral ao poder, um processo de secularização foi colocado em marcha e pouco a pouco o Québec foi se desvencilhando da influência política da Igreja Católica. Para maiores detalhes, ver Pelletier (2010). 
Sociologias, Porto Alegre, ano 17, no 39, mai/ago 2015, p. 248-275

o acordo Cullen-Couture ${ }^{3}$ (transformado em lei no mesmo ano) através do qual o Québec e o Canadá passariam a dividir de forma paritária as responsabilidades no processo de recrutamento de imigrantes. Graças a esse acordo, o Québec conquistava o direito de estabelecer critérios de seleção específicos que seriam aplicados basicamente ao conhecimento da língua francesa. Ainda em 1978, por meio do documento intitulado Política Quebequense de Desenvolvimento Cultural, o governo do Québec decide enfrentar a política multicultural do Canadá, considerada uma ameaça à autonomia e à preponderância local da identidade e da língua francesa. Apenas dois anos após a elaboração daquele documento, através da Carta da Língua Francesa, o francês torna-se a língua oficial e obrigatória no Estado do Québec. Era o início do interculturalismo como política oficial, a qual partia do princípio que o Québec não era simplesmente uma província da federação, mas uma nação no sentido cultural e político do termo (HOULE, 1999).

A trajetória em direção à autonomia sobre a política de imigração conheceria, no ano de 1981, um novo e importante capítulo quando o MIQ passa a ser denominado de Ministério das Comunidades Culturais e da Imigração $(\mathrm{MCCl})$. A mudança não foi apenas formal, porque, de fato, pela primeira vez, os grupos de imigrantes passam a ser classificados genericamente como comunidades culturais ${ }^{4}$. Em resposta à ambiguidade criada, nesse mesmo ano de 1981, é apresentado o Plano de Ação do Governo do Québec para as Comunidades Culturais. Nesse texto, ao mesmo tempo em que reconhecia a realidade multicultural definida no âmbito do Estado do Canadá, o Québec reafirmava o eixo principal de sua políti-

\footnotetext{
${ }^{3}$ Assinado em 20 de fevereiro de 1978 por Jacques Cullen, do Ministério do Emprego e da Imigração do Canadá e Jacques Couture, do MIQ.

${ }^{4} \mathrm{~A}$ definição de comunidades culturais trazia apenas um denominador comum: o fato de não pertencerem à maioria francesa. Para maiores detalhes, ver Fontaine (1993).
}

http://dx.doi.org/10.1590/15174522-017003911 
Sociologias, Porto Alegre, ano 17, no 39, mai/ago 2015, p. 248-275

ca: a integração de todos os imigrantes à sociedade quebequense, tendo por base o uso da língua francesa. Em consequência, o governo tornava oficial o fait français, transformando o conhecimento linguístico em forma de classificação e de identificação dos imigrantes. Em termos práticos, todos os imigrantes que não tinham as línguas inglesa ou francesa como línguas maternas, chamados então de alófonos, seriam bem-vindos ao Québec desde que aceitassem se converter à língua francesa.

Até ser definitivamente abandonado em 1990, o acordo constitucional de 1987, conhecido como Meech Lake Accord, que reconhecia o Québec como uma sociedade distinta, foi o principal instrumento legal para que a província desenvolvesse sua própria política de imigração. Mas após a não ratificação desse acordo, o governo federal do Canadá e o Québec assinaram novo pacto em matéria de imigração, o chamado Acordo Canadá-Quebec Relativo à Imigração e à Admissão Temporária de Estrangeiros, através do qual a província passava a controlar integralmente o processo migratório. Enfim, o documento Enunciado Político em Matéria de Imigração e de Integração, publicado às vésperas da entrada em vigor desse novo acordo, apresentava os novos objetivos em matéria de imigração: recuperação demográfica, prosperidade econômica, perenidade do fait français e abertura ao mundo (MCCl, 1991). Os eixos da ação eram a intensificação dos serviços de ensino do francês e a abertura da coletividade francófona às pessoas de origens diversas. Através desse acordo e do documento que o precedeu, ficou estabelecido, de forma bastante clara, a relação entre a vitalidade do fait français, considerado o elemento mais significativo do Québec moderno (MCCl, 1991, p. 10) e a imigração, considerada a única possibilidade de estancar a queda proporcional da população quebequense em relação à população total canadense ${ }^{5}$.

${ }^{5}$ Segundo o Enunciado (MCCl, 1991, p. 10), a participação da população quebequense caiu $3 \%$ em relação à população canadense nas últimas duas décadas, devido sobretudo ao déficit de imigrantes e à taxa de fecundidade declinante. 
A execução do Acordo de 1991 esbarrou, contudo, na ausência de infraestrutura burocrática. Assim, a desejada abertura ao mundo restringiu-se inicialmente a países como o Haiti ou o Marrocos que, embora considerados periféricos pelo governo do Quebec, ainda eram francófonos. Assim, se entre 1970 e 1980, a média dos imigrantes cuja língua materna era o inglês alcançou 39\% do total que se instalaram no Québec, entre os anos de 2000 e 2003, esse percentual não chegou a 17\%. Contudo, no início dos anos 2000, a imigração oriunda de outras regiões do mundo, como, por exemplo, a América Latina, ainda era pouco importante ${ }^{6}$. Mas para além da política de seleção e recrutamento de imigrantes, o Enunciado de 1991 previu a gestão da diversidade cultural existente (e esperada), organizando para isso um novo tipo de política de integração.

Respeitando as diretrizes do $\mathrm{MCCl}$, os imigrantes foram classificados segundo sua região de origem como Quebequenses de Comunidades Culturais. Essa nova categoria indicava a vontade de romper com os limites tradicionais do Québec étnico, i.e., franco-canadense, abrindo a sociedade à participação de outros grupos de imigrantes. Nessa nova configuração, a sociedade quebequense foi definida por três princípios gerais:

Uma sociedade onde o francês é a língua comum;

Uma sociedade democrática onde a participação e a contribuição de todos são esperadas e incentivadas;

Uma sociedade pluralista, aberta às múltiplas contribuições, guardados os limites que impõem o respeito aos valores democráticos fundamentais e a necessidade da troca intercomunitária. (MCCl, 1991)

Uma vez definido o francês como língua oficial, todos os membros das outras comunidades de imigrantes foram chamados a contribuir com

\footnotetext{
${ }^{6}$ Segundo Linteau (2009, p. 38), era surpreendente ver o pequeno número de latino-americanos que chegavam ao Canadá em comparação ao número que chegava aos EUA. A tradução é de nossa responsabilidade.
} 
a nação quebequense, ou seja, a se integrar no todo nacional. Deveriam fazê-lo sempre de forma intercomunitária, ou seja, não se restringindo a seu próprio grupo. Com essa política, o governo do Québec demonstrava preocupação em não isolar os grupos de imigrantes entre si, mas essas ações logo mostraram seus limites. Em 1996, o MCCI muda novamente de nome passando a ser denominado de Ministério das Relações com os Cidadãos e da Imigração (MRCl). Esta mudança demonstrou que havia certa incoerência nas ações do antigo ministério da imigração, cujo foco eram as comunidades culturais, mas cuja política de seleção e recrutamento assentava-se em um sistema de pontos atribuído a cada imigrante em particular. Além disso, estava claro que o desejo de integração via participação política era uma decisão individual e não comunitária. Notou-se, finalmente, que o peso atribuído às comunidades culturais estaria colocando em risco o sentido do interculturalismo que reforçava a proeminência do fait français, ou seja, da grande comunidade francófona sobre todas as demais.

Em 2005, porém, houve outra mudança. O MRCl, retomando a antiga expressão das comunidades culturais, passa a ser denominado de Ministério da Imigração e das Comunidades Culturais (MICC). Em relação ao antigo nome de $\mathrm{MCCl}$, a diferença era praticamente inexistente, pois apenas os termos imigração e comunidades culturais haviam mudado de posição. Contudo, a nova denominação teve um sentido político claro. Finalmente o Québec se considerava pronto para priorizar, no campo da imigração, as comunidades não francófonas. Em consequência, pela primeira vez, a imigração latino-americana em geral, e brasileira em particular, vão tornar-se objeto da política local e suas taxas relativas vão apresentar significativa elevação, como veremos a seguir.

Ao lado das comunidades culturais, o governo adotou também a categoria de minorias visíveis, como parte do leque de alternativas jurí- 
Sociologias, Porto Alegre, ano 17, no 39, mai/ago 2015, p. 248-275

dico-sociais destinadas a classificar os imigrantes não europeus. Rigorosamente falando, o governo não criava aí uma nova categoria jurídica, mas passava apenas a aplicar a Lei sobre a Igualdade em Matéria de Emprego aos novos imigrantes. Sancionada em 1986, seu objetivo foi o de impedir ações preconceituosas contra indivíduos classificados em quatro grupos, a saber: as mulheres, os portadores de necessidades especiais, os autóctones e, finalmente, as minorias visíveis. Em 1986, o órgão federal de estatísticas (Statistics Canada) utilizou esse termo em seu recenseamento. Foram classificados como minorias visíveis os seguintes grupos: negros, latino-americanos, árabes, chineses, sul-asiáticos, asiáticos ocidentais, asiáticos do sudoeste, japoneses, coreanos, além de outros grupos originários de ilhas do Pacífico.

De acordo com o Statistics Canada (2008), a proporção de minorias visíveis no país, que era de 4,7\% em relação à população total em 1981, chegou a 16,2\% em 2006. No caso do Québec, em 2006, negros e árabes eram as minorias mais importantes, representando $8,8 \%$ da população total, perfazendo, porém, $17 \%$ da população se considerada apenas a região de Montreal. Enfim, no período de 2001 a 2006, árabes e latino-americanos foram as minorias que registraram maior taxa de crescimento, com $48,6 \%$ e $51 \%$ respectivamente. Não obstante, aqui, como no caso anterior das comunidades culturais, havia certa incompatibilidade entre a categoria de classificação e o processo de recrutamento, ainda definido em função do grau de adaptação de cada indivíduo. Com efeito, nos documentos governamentais, não há um padrão de adaptação que pudesse ser deduzido do pertencimento a qualquer minoria visível. Ao contrário, o perfil profissional era a variável mais importante tanto na seleção quanto no processo de integração. Embora o governo do Québec soubesse disso, é possível dizer que a abertura de Escritórios na América Latina pode ter decorrido da avaliação positiva do grau de adaptação e também do perfil profissional da minoria latino-americana.

http://dx.doi.org/10.1590/15174522-017003911 
Os chamados acordos razoáveis são a última figura jurídica que mostram os grandes desafios da política de integração do Québec. Surgida em 1985 no quadro dos conflitos entre patrões e empregados, os pedidos de conciliação acabaram por ultrapassar a esfera trabalhista, sendo chamados muitas vezes para dirimir situações cotidianas entre imigrantes e canadenses, como por exemplo, o direito ao uso de símbolos religiosos nas escolas. Foi no contexto da chamada crise dos acordos razoáveis que o governo do Quebec instituiu, em 2007, a Comissão de Consultas sobre as Práticas de Conciliação Referentes às Diferenças Culturais, presidida conjuntamente pelo sociólogo Gérard Bouchard e pelo filósofo Charles Taylor. Em seu relatório final, a Comissão mostrou que a grande maioria das demandas era de caráter religioso, e não necessariamente indicavam problemas na integração dos imigrantes ${ }^{7}$.

Em seguida aos trabalhos da Comissão, o MICC publicou três planos de ação, sob o título geral de Para Enriquecer o Québec: integrar melhor (MICC, 2008a, 2008b, 2008c). Nesses, algumas iniciativas chamavam a atenção. Primeiro, a oferta de cursos de francês aos imigrantes já instalados no Québec. Segundo, o estabelecimento de parcerias com escolas de língua instaladas no exterior, para a oferta de cursos de francês, cujas despesas ficariam sob a responsabilidade dos candidatos à seleção ou daqueles que já estariam selecionados. Em terceiro lugar, a assinatura, pelo candidato à imigração, de uma declaração de conhecimento dos valores comuns à sociedade quebequense.

À diferença da justaposição dos grupos que inspiraram a política multicultural canadense, o governo do Québec preferiu uma estrutura hierárquica reunindo apenas duas categorias de indivíduos. De um lado,

${ }^{7} \mathrm{~A}$ Comissão apontou ainda para a reação exagerada da mídia às demandas das minorias religiosas e na acentuação dos estereótipos. (BOUCHARD; TAYLOR, 2008). 
Sociologias, Porto Alegre, ano 17, no 39, mai/ago 2015, p. 248-275

os indivíduos pertencentes à nação quebequense e de outro, os indivíduos classificados como comunidades culturais ou minorias visíveis. As relações que ligavam à nação às comunidades ou às minorias permaneceriam excludentes na medida em que a província do Québec continuava, na prática, referindo-se apenas aos francófonos. Porém, eram inclusivas porque os membros desses outros grupos eram convocados a se integrar a ela. Dito de outro modo, aqueles que nasceram fora do Canadá ou cuja língua materna não era o francês, embora não contemplados na definição de nação do Québec, seriam chamados a fazer parte dela (LABELLE; ROCHER e ROCHER, 1995).

Em resumo, as categorias de comunidades culturais, de minorias visíveis e os processos de acordos razoáveis indicavam os múltiplos aspectos da relação da província com seus imigrantes. Traduziam principalmente o esforço em integrar os novos imigrantes à sociedade local sem, contudo, descuidar dos interesses mais gerais de recuperação demográfica e de prosperidade econômica. Demonstram ainda que a província havia conseguido afirmar-se política e burocraticamente diante da federação canadense. Mas evidenciam, sobretudo, o papel, muitas vezes involuntário, que o conjunto dos imigrantes tinha nesse processo e o decisivo papel que os não francófonos teriam a partir dos anos 2000. Contudo, pouco havia sido dito a respeito dos próprios imigrantes, nem mesmo da forma como eles vivenciaram as ações a eles destinadas. Seria correto dizer que os imigrantes eram apenas peças manipuláveis no jogo político do Québec? E que dizer dos brasileiros, incluídos na comunidade latino-americana? 


\section{Cidadania e capital de mobilidade: os imigrantes como agentes e os limites da política de integração quebequense}

No Canadá, segundo dados do recenseamento de 2006, havia 15.120 imigrantes cujo local de nascimento (e primeira cidadania declarada) era o Brasil (STATISTICS CANADA, 2014). Em 2012, a população total de origem brasileira, agrupando os dados oficiais a partir de 1976, era de 5396 imigrantes, independente do fato de terem nascido no Brasil ou no Canáda ${ }^{8}$ (MICC, 2012) ${ }^{9}$. Entre 2001 e 2010, foram admitidos 3.901 imigrantes na categoria imigração econômica, aquela que contempla os trabalhadores qualificados. Além desses, temos 617 imigrantes admitidos na categoria reagrupamento familiar, 20 na categoria refugiados e 5 na categoria outros, não especificada. No total, temos então 4.544 imigrantes brasileiros admitidos nesse período, sendo que desses, 3.631 ainda residiam no Québec no ano de 2012, perfazendo uma taxa de retenção de 79,9\% (MICC, 2013).

Os dados aqui analisados foram coletados por meio de um formulário - contendo questões abertas e fechadas - preenchido online ${ }^{10} \mathrm{e}$ de maneira voluntária. Os imigrantes respondentes foram convidados ${ }^{11} \mathrm{a}$ participar da pesquisa a partir de contatos diretos com brasileiros morando no Québec, de uma lista de endereços eletrônicos pessoais de dois

\footnotetext{
${ }^{8}$ Lembremos que nascer no Canadá não implica na aquisição imediata da cidadania canandense. ${ }^{9}$ Os dados mais recentes sobre o número de imigrantes brasileiros no Québec, publicados pelo Ministère de l'Immigration et des Communautés Culturelles, datam de março de 2012.

${ }^{10} \mathrm{O}$ software utilizado na aplicação do formulário permitiu a geolocalização dos respondentes por meio de endereço IP (Internet Protocol), verificando assim que todos foram preenchidos no Québec.

${ }^{11}$ Como critério, os respondentes deveriam ter se submetido ao processo de imigração baseado no sistema de pontos para categoria travailleur qualifié e estar residindo no Québec no momento da pesquisa. Assim, foram excluídos imigrantes temporários, tais como empresários e estudantes.
} 
Sociologias, Porto Alegre, ano 17, no 39, mai/ago 2015, p. 248-275

informantes residentes no Québec e do grupo de discussão do Google chamado Casa do Brasil em Québec. Ao final, obtivemos 83 formulários respondidos de forma completa ${ }^{12}$, sendo o primeiro em junho de 2011 e o último em abril de 2012. Desse total de 83 respondentes, 42,2\% estão na faixa etária entre 31-35 anos, seguidos daqueles que possuem entre 26-30 anos (25,3\%). Aproximadamente $33 \%$ afirmaram ter proficiência do francês e $8,4 \%$ dos respondentes eram solteiros no momento da pesquisa.

Como visto, a partir da entrada em vigor do acordo entre o Québec e o Canadá (1991), a província abriu Escritórios de Imigração em diferentes países como forma de conciliar a abertura ao mundo com o recrutamento de trabalhadores qualificados com proficiência em língua francesa. A escolha do país de instalação de um Escritório era consequência do modo como a província operava a categoria de bassin d'immigration ${ }^{13}$, que poderia corresponder a um país, um grupo de países, um continente ou parte de um continente (MICC, 2007, p. 10). Mas mesmo que a zona geográfica fosse variável, o critério de seleção mais importante, justamente aquele que deveria garantir a perenidade do fait français, continuava sendo a familiaridade com a língua francesa. Aqui surgiu o paradoxo. Embora o Estado soubesse que o conhecimento da língua francesa e a formação profissional dos candidatos à imigração eram realmente decisivos no processo de integração, os candidatos oriundos das novas áreas, por definição, não falavam francês. Assim, para incentivar o domínio do francês e mostrar como isso seria central no processo de integração, o MICC publicou uma brochura direcionada aos candidatos à imigração, intitulada O sucesso por meio do francês: cabe a você agir! Em seu conteúdo, estava dito: Cabe a você agir, construir seu futuro... em francês! [...]

\footnotetext{
${ }^{12}$ Ao longo do texto, os depoimentos utilizados aparecem identificados pelo número do formulário.

${ }^{13}$ Em tradução livre, área de imigração.
} 
Aprender o francês antes de partir é preparar seu futuro de forma cuidadosa e inteligente! ${ }^{14}$. (MICC, 2009, p. 2). Lentamente, a francisation - ou seja, o aprendizado do francês e o conhecimento da realidade social e cultural do Québec antes mesmo da imigração ${ }^{15}$ - tornar-se-ia a principal ferramenta na política de seleção e de integração, organizada pela província francófona.

O Brasil, devido ao nível educacional e profissional de parte de sua população, era candidato a se tornar uma área de imigração. Mas para que isso acontecesse, os candidatos que se enquadrassem nos critérios de seleção - idade, escolaridade e profissão - deveriam adquirir o capital linguístico específico, iniciando ou melhorando seus conhecimentos de francês e da própria história do Québec. Para isso, o Québec solicitou que as escolas da rede Aliança Francesa ${ }^{16}$ adaptassem seus cursos para o francês quebequense e que transmitissem aos candidatos informações sobre o processo de imigração. Outra importante ferramenta de promoção do processo de imigração do Québec foram as Palestras de Informação, cujo objetivo era tratar de assuntos relacionados às etapas do processo migratório, à procura de trabalho e mesmo à própria sociedade quebequense. No Brasil, estas palestras aconteceram isoladamente de 2005 até 2008, quando foi aberto o Escritório na cidade de São Paulo. A partir daí, elas foram mais frequentes, além de terem sido realizadas em outras cidades. Em 2010 foram ministradas 73 palestras de informação, para um público de mais de 12.000 pessoas

\footnotetext{
${ }^{14}$ No original: $\grave{A}$ vous d'agir, à vous de construire votre avenir... en français! [...] Apprendre le français avant votre départ, c'est préparer soigneusement et intelligemment votre avenir!

${ }^{15}$ No documento de seleção do MICC, lia-se: Francisar mais cedo, oferecendo aos indivíduos selecionados a oportunidade de aprender o francês antes mesmo de sua chegada ao Québec. (MICC, 2008a, p. 6). O objetivo era transmitir os valores e a história do Québec, para além do conhecimento da língua francesa em si, de modo a favorecer o processo de integração.

${ }^{16}$ Outras escolas de ensino surgiram com o mesmo objetivo. É o caso da École Québec < http:// www.ecolequebec.com.br> que funciona em São Paulo e no Rio de Janeiro, e Centre Québec $<$ http://www.centrequebec.com.br>, que funciona em Curitiba.
} 
Sociologias, Porto Alegre, ano 17, no 39, mai/ago 2015, p. 248-275

(MRI, 2012, p. 2). As palestras que reuniram maior número de interessados ocorreram nas cidades de São Paulo, Curitiba, Salvador e Brasília.

As ações do Québec foram eficazes. Entre 2008 e 2010, houve um aumento de 31\% de emissões do Certificado de Seleção do Québec (CSQ). Em 2008, foram emitidos 1031 CSQ e em 2010, 1427 (MRI, 2010). Ligando esse crescimento à categoria administrativa de área de imigração que, agora, incluía imigrantes não francófonos como os brasileiros, verifica-se que o imigrante ideal não era mais aquele que estava profissionalmente pronto, ou seja, aquele que mais se aproximava da definição de trabalhador qualificado, mas sim aquele que buscava adequar-se à nova realidade, incluindo aí o aprendizado da língua francesa no país de origem. Esse sentido de adequação pôde ser evidenciado inicialmente quando da entrevista para a obtenção do Certificado, que passou a ser conduzida em francês.

O sentido criterioso da seleção pôde ser verificado também analisando elementos objetivos, como, por exemplo, a comprovação dos documentos. Além disso, durante a entrevista no Escritório, a apresentação do projeto de vida, ou seja, a descrição detalhada daquilo que se pretendia realizar no Québec, bem como os meios para alcançar esse fim, passou a ser percebida pelos Escritórios de imigração como elemento revelador da adequação do candidato às particularidades da sociedade quebequense e da adesão ao fait français, configurando-se aí um aparente compromisso que ultrapassava a questão legal. A decisão Vous avez été accepté - você foi aceito -, emitida pelo agente de imigração, consolidaria essa relação envolvendo, de um lado a figura institucional do Estado que chancela e, de outro, a figura do imigrante que se adequou aos parâmetros fixados.

Na pesquisa, verificamos que a competência linguística era a principal preocupação tanto do candidato quanto do Escritório, embora de forma diferente. Enquanto que para a província, o domínio da língua sig-

http://dx.doi.org/10.1590/15174522-017003911 
Sociologias, Porto Alegre, ano 17, no 39, mai/ago 2015, p. 248-275

nificava a adesão ${ }^{17}$ aos interesses do Québec, para o candidato à imigração, significava maior chance de inserção no mercado de trabalho. A integração podia ser iniciada com o aprendizado da língua francesa e dos elementos culturais que ela representa para o Québec, mas, fundamentalmente, como a pesquisa demonstrou, a inserção no mercado de trabaIho era realmente o elemento decisivo no sucesso do percurso migratório.

No caso do Québec, como analisam Chicha e Charest (2008), vários indicadores demonstram a realidade que os imigrantes encontram no mercado de trabalho e os possíveis fatores de exclusão: inferiorização profissional, menor competência linguística, dificuldades para o reconhecimento de diplomas estrangeiros, falta de experiência de trabalho em território canadense e... pertencimento a uma minoria visível. Lembremos que, no contexto analisado, os imigrantes foram selecionados a partir de uma política ativa de recrutamento de trabalhadores qualificados.

Após fixar residência, os imigrantes eram classificados por meio das categorias de minorias e comunidades. No caso das minorias, a administração pública do Québec se vale da autodeclaração dos indivíduos como critério de identificação ${ }^{18}$. De forma geral, a ascendência hispânica e a origem geográfica explicam porque os latino-americanos assim se autodeclaram. Porém, essa lógica de identificação não se encaixou à realidade dos brasileiros. Mesmo quando se declaravam latino-americanos, eles não se reconheciam totalmente como membros dessa minoria visível. Em consequência, um dos fatores que marcou o percurso migratório

\footnotetext{
${ }^{17} \mathrm{O}$ sentido de adesão, segundo os documentos citados - em particular o Enunciado Político em Matéria de Imigração e de Integração $(\mathrm{MCCl}, 1991)$ - refere-se à capacidade do candidato em reconhecer a interculturalidade da sociedade quebequense e a centralidade da língua francesa.

${ }^{18}$ Bourdieu (1996, p. 72) analisa a manifestação do poder simbólico do Estado como um poder de nomeação, cuja ideia fundamental é a de que ao nomear, faz existir. Já em relação aos imigrantes, Noiriel (2001) apresenta as formalidades administrativas ligadas à identificação civil como elemento de assimilação nacional.
} 
dos brasileiros no Québec foi, justamente, o afastamento voluntário de uma identidade imigrante relacionada à minoria visível latino-americana, o que explica sua relativa ausência nos dados oficiais, mas que, por outro lado, talvez explique suas particulares trajetórias de integração.

Os mecanismos sociais de integração e de superação da exclusão foram objeto de vários estudos. Brito (2010) descreve o desenvolvimento de um habitus de migrante que, ao dotar os imigrantes de recursos práticos para enfrentar um novo espaço social, favoreceria a mobilidade. Freitas (2009) afirma que o potencial de mobilidade seria composto pelas disposições de classe, pelo capital cultural e pela participação em programas de expatriação de organizações privadas. Os argumentos desses dois autores guardam relação com a teoria da prática desenvolvida por Bourdieu (1996). Nas práticas sociais dos imigrantes brasileiros na sociedade de acolhimento, vimos que seu habitus e capital escolar efetivamente facilitaram sua mobilidade horizontal e/ou vertical e, assim, sua integração. Mas, em alguns casos, ao lado dos outros tipos de capital (cultural, simbólico, etc.), surgiu um novo, aqui chamado de capital de mobilidade ${ }^{19}$, que teria a mesma capacidade de facilitar a integração mas que, potencialmente, poderia ser usado mais tarde em qualquer outra situação, inclusive em nova migração. Esse novo tipo de capital adquirido expressaria as novas formas de transnacionalismo em um mundo globalizado, como descreve Appadurai (1997), quando as tradições nacionais são controladas, e os imigrantes delas se servem estrategicamente. Enfim, esse novo capital explicaria a demanda por cidadania e apontaria os limites da política de integração quebequense via minorias e comunidades culturais, como mostramos a seguir.

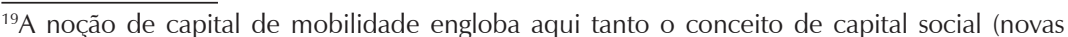
relações sociais) quanto o de capital simbólico (aprendizado das regras do jogo), funcionando assim como trunfos num jogo de adaptação não apenas no lugar esperado, no caso o Québec, mas em qualquer outro, no caso de uma remigração. Para o conceito de capital, ver Bourdieu (2002, p. 135).
} 
Sociologias, Porto Alegre, ano 17, no 39, mai/ago 2015, p. 248-275

Analisando as respostas contidas no formulário aplicado, verificamos que $61,5 \%$ dos imigrantes brasileiros residentes no Québec efetivamente identificam-se apenas como parte de uma comunidade cultural de imigrantes, afastando-se tanto da identidade latino-americana (16,9\%) quanto da brasileira $(21,7 \%)$. Há ainda aqueles que declararam não fazer parte de nenhuma comunidade cultural $(16,9 \%)$.

Tabela 1

\begin{tabular}{l|l}
\hline IDENTIFICAÇÃO COM UMA COMMUNAUTÉ CULTURELLE & (\%) \\
\hline Eu acredito fazer parte da comunidade cultural dos imigrantes, considerados & 44,6 \\
Como um todo. & 16,9 \\
Eu acredito fazer parte da comunidade cultural dos latino-americanos & 21,7 \\
Eu acredito fazer parte da comunidade cultural dos brasileiros & 16,9 \\
\hline Eu não acredito fazer parte de nenhuma comunidade cultural &
\end{tabular}

O fato da maioria dos respondentes declarar não fazer parte de nenhuma comunidade cultural específica deveria surpreender, mas os depoimentos sobre o significado do termo intercultural na sociedade quebequense revelaram as razões disso.

De maneira geral a população é receptiva e eu nunca sofri nenhum tipo de preconceito aparente durante os anos que vivo aqui. Geralmente os brasileiros conseguem se integrar mais facilmente, pois passam despercebidos pela população. [...] Por sermos também um país de imigrantes e de origem católica, a nossa integração é facilitada. [...] Porém, um fenômeno que acontece é a falta da total integração [dos outros] imigrantes com a sociedade. (f.. 84)

Porque é uma comunidade de imigrantes. O difícil é os Québécois viverem com a diversidade. (f. 80)

Muitas culturas, mas pouca integração. As pessoas se fecham em guetos. (f. 34)

http://dx.doi.org/10.1590/15174522-017003911 
Sociologias, Porto Alegre, ano 17, no 39, mai/ago 2015, p. 248-275

O Brasil neste aspecto é mais intercultural que o Québec. Aqui, a sociedade ainda não se mistura. Ela é algo que poderíamos definir como 'multicultural'... mas não Intercultural. No Brasil, temos realmente uma mistura, e uma inter-relação entre diferentes culturas. Lembro-me de conhecer dois amigos no Brasil, onde um era judeu e o outro libanês, e os dois adoravam futebol no domingo, mas antes iam às suas respectivas sinagoga e mesquita, e conviviam pacificamente. Aqui existe um grupo de hispânicos, outro de chineses, outro de mulçumanos (não importa se árabes ou persas)[...] Como falar em uma grande comunidade intercultural, se ela é feita de pequenas comunidades fechadas em suas próprias culturas? Mas existe uma troca... festas exóticas latinas, que os quebequenses gostam de ver como folclore e 'alienígena'.....] (f. 33)

Como mostram os depoimentos acima, não fazer parte de nenhuma comunidade cultural (passar despercebido), desvinculando-os de atributos comunitários particulares, foi a consequência de não se sentirem diferentes. Os imigrantes brasileiros apontaram elementos culturais que eles têm em comum com os cidadãos quebequenses, como a religião católica. Além disso, por serem oriundos de um país em que a miscigenação e a imigração são parte da identidade nacional, não se reconheceram naquele modelo intercultural. Embora as categorias oficiais quebequenses - comunidades culturais e minorias visíveis - tenham a intenção de facilitar o processo de integração, os percursos migratórios dos imigrantes brasileiros, ao passar despercebidos pela sociedade de acolhimento, moldaram uma maneira peculiar de lidar com as políticas de integração. De certa forma, era como se não tivessem lição a receber da política oficial de integração porque já sabiam como se integrar! Compreende-se assim porque a interculturalidade do Québec foi questionada. No Brasil, afirmou um dos imigrantes, há mistura, inter-relação, enquanto que o Canadá seria multicultural. Os respondentes demonstravam sentir-se egressos de uma realidade que havia desenvolvido uma 
Sociologias, Porto Alegre, ano 17, no 39, mai/ago 2015, p. 248-275

atitude intercultural mais pronunciada do que a quebequense. Tudo isso trabalhou em favor de uma integração exitosa, mas, paradoxalmente, apontou, senão para uma oposição entre integração e o pertencimento a grupos oficialmente reconhecidos, ao menos para os limites das ações da política oficial. Mas se as categorias sociais oficiais não contribuíam com a integração, quais fatores contribuiriam?

A opinião dos brasileiros em relação à demanda da cidadania canadense revelou outra dimensão da complexa relação entre percurso migratório, integração, participação política e... mobilidade! Em alguns depoimentos colhidos, ficou claro que a condição de imigrante não é necessariamente vista como definitiva.

Eu espero ter minha origem brasileira apenas como parte do meu passado. Sou canadense desde setembro. (f. 81)

Eu já pedi a cidadania. Para ter direito de entrar em outros países sem precisar de visto. (f. 24)

Sim. Fácil acesso a Europa e EUA. Passaporte mais aceito que o Brasileiro. (f. 22)

Já demandamos a cidadania canadense. Queremos poder votar e participar mais ativamente do processo político do país e também achamos que o passaporte canadense abre portas. (f. 46)

Acredito que a cidadania é importante para o imigrante no sentido de maior comprometimento com o país. E no meu caso por ter optado em somente trabalhar, a cidadania canadense pode contar na minha experiência profissional. (f. 32) Vou pedir a cidadania. Pois quero ser canadense. Com o passaporte Canadense tenho portas abertas em muito mais países do que como brasileiro. (f. 11)

Com a cidadania [...] se algum dia eu quiser voltar para o Brasil, eu terei o direito de ir e voltar quando eu desejar. (f. 9)

Aparentemente, o processo de integração é mais dinâmico do que supõem os documentos oficiais, e não implica necessariamente na permanência definitiva na sociedade de acolhimento. A demanda de cida- 
dania demonstra que tanto a possível adesão ao fait français quanto o distanciamento das minorias visíveis ou das comunidades culturais têm que ser entendidos em sua dupla dimensão cultural e instrumental, em especial no que se refere ao mercado de trabalho, à participação política e às possibilidades futuras que o passaporte canadense oferece. Para alguns imigrantes brasileiros, o principal motivo para obtenção da cidadania canadense é a facilidade ${ }^{20}$ de trânsito entre países, em particular os EUA, que não exigem visto para cidadãos canadenses, mas sim para brasileiros. A obtenção da cidadania revela aqui a dimensão internacional do citado capital de mobilidade.

No plano interno, há grande vantagem também porque ser cidadão canadense acaba por legitimar a experiência profissional tanto passada graças à regularização dos diplomas brasileiros - quanto àquela adquirida, aumentando o leque de possibilidades de acesso ao mercado de trabalho. Mas há enfim aqueles que simplesmente associam a obtenção da cidadania ao que chamam de processo natural de integração. Ao contrário do que se poderia supor, é rara a associação entre a cidadania canadense e a adesão estrita ao fait français. Com efeito, após a obtenção da cidadania, a oficialmente desejada participação democrática liga-se diretamente ao país, e não apenas à província do Québec. Isso também demonstra os limites do interculturalismo quebequense. Os imigrantes reconhecem as vantagens da cidadania na própria sociedade de acolhimento e em contextos sociais que ultrapassam a política como, por exemplo, a associação entre cidadania e o reconhecimento de sua experiência profissional no mercado de trabalho local. Mas, é claro, a cidadania canadense também está relacionada à posse de um novo passaporte, documento que valida a identidade adquirida perante as autoridades policiais de controle de fron-

${ }^{20}$ Essa facilidade deve ser compreendida em um contexto de formação de um mercado de trabalho transnacional, como afirma Sassen (2010). 
teiras de qualquer país. Numa palavra, para os imigrantes, a convergência cultural parecer ser muito menos importante do que a segurança jurídica que a obtenção da cidadania canadense oferece ${ }^{21}$, e mesmo do que a segurança econômica que o trabalho propicia.

\section{Considerações Finais}

A pesquisa mostrou que, no Québec, o imigrante brasileiro afasta-se de uma identidade latino-americana, de minoria visível, ao mesmo tempo em que reivindica uma proximidade sociocultural com a sociedade local. Essas práticas o diferenciam de outros grupos de imigrantes. Negando as diferenças étnicas, ressaltando semelhanças, enfim, servindo-se de seus capitais, faz valer uma identidade que o auxilia a transpor potenciais obstáculos, principalmente no que diz respeito ao mercado de trabalho. E, por mais óbvio que isso possa parecer, tais ações só são possíveis porque carregam habitus de brasileiros, ou seja, habitus de uma cultura mestiça e multicultural. Em sentido inverso, a interculturalidade quebequense identificando os grupos de imigrantes como diferentes do padrão cultural local - parece estar, no caso dos brasileiros, dificultando a integração.

O percurso migratório dos brasileiros apresentou outras dimensões para além da integração à sociedade de acolhimento. Todos os investimentos que os imigrantes brasileiros realizaram no processo de migração tornaram-se partes de um capital de mobilidade, que pode ser acionado caso os objetivos do percurso migratório naquela sociedade de acolhimento não se concretizem. Isso mostra que o imigrante não é apenas o objeto das políticas migratórias, mas também alguém que atua como um operador prático dos interesses em jogo (BOURDIEU, 1996). Por mais

$\overline{{ }^{21} \text { Nos documentos }}$ governamentais do Québec, a demanda por cidadania não figura no rol das políticas de integração. 
que a experiência bem sucedida no mercado de trabalho esteja relacionada à permanência do imigrante na província, a adesão ao fait français, também considerada essencial pelo governo, é vista como secundária pelos imigrantes. Dito de outro modo, foi possível verificar que, para os imigrantes brasileiros, as questões ideológicas que compõem o processo migratório - incluindo todo discurso relativo à adesão ao fait français - não se sobrepõem ao sentido pragmático do percurso migratório. Um indicador dessa distância entre os objetivos políticos do processo migratório e o resultado prático do percurso migratório encontra-se, como vimos, na opinião dos imigrantes sobre a aquisição da cidadania. Há um valor simbólico da cidadania canadense que se eleva acima de uma identidade quebequense e mesmo acima do vínculo à sociedade nacional. Esse valor é percebido pelos imigrantes como possibilidade de iniciar um novo percurso migratório com mais vantagens do que o anterior, pois ele conseguiu acumular mais capital de mobilidade.

Em síntese, a identidade social definida na esfera do Estado é claramente manipulada pelo imigrante brasileiro, seja afastando-se da classificação de minoria visível, seja fazendo-se valer de outras características facilitadoras do processo de integração, como, por exemplo, o fato de ser católico, seja ainda obtendo a cidadania. Nas práticas diante dos outros e do fait français do Estado do Québec é que se encontra a relevância desse grupo de imigrantes. Num plano mais geral, o caso analisado parece demonstrar os limites do processo de integração em um mundo globalizado. Parece demonstrar, enfim, que a condição de imigrante é vivida hoje de maneira muito diferente do que já foi no passado.

Márcio de Oliveira - Professor titular de Sociologia da Universidade Federal do Paraná. Formado em Ciências Sociais pela Universidade de Brasília (1983), mestrado em Sociologia (1987) e doutorado em Sociologia (1993), pela Universidade de Paris V, com pós-doutorado em Sociologia (EHESS-MSH, Paris, 2008). Consultor do INEP, Fundação Araucaria de Apoio à pesquisa (Paraná), CNPq e da CAPES. $\sum$ marciodeoliveira@ufpr.br 
Sociologias, Porto Alegre, ano 17, no 39, mai/ago 2015, p. 248-275

Fernando Kulaitis - Professor na Universidade Tecnológica Federal do Paraná. Doutor em Sociologia pelo Programa de Pós-Graduação em Sociologia da Universidade Federal do Paraná, com estágio de doutorado na Université Sorbonne Nouvelle (Paris 3), Institut des Hautes Études de l'Amérique Latine, possui mestrado em Sociologia (UFPR, 2004) e graduação em Ciências Sociais (UFPR, 2002). $\sum$ fernando.kulaitis@gmail.com

\section{Referências}

1. APPADURAI, Arjun. Soberania sem territorialidade. Notas para uma geografia pós-colonial. In: Novos Estudos, n. 49, nov. 1997, p. 33-46.

2. BOUCHARD, Gérard; TAYLOR, Charles. Fonder I'avenir. Rapport. Commission de Consultations sur les Pratiques d'Accommodement Reliées aux Différences Culturelles. Québec, 2008. Disponível em: <http://www.accommodements-quebec.ca/documentation/rapports/rapport-final-integral-fr.pdf $>$. Acesso em: 15 mar. 2011.

3. BOURDIEU, Pierre. Espaço social e gênese das classes. In: BOURDIEU, Pierre. O poder simbólico. 5. ed. Rio de Janeiro: Bertrand Brasil, 2002. p. 133-162.

4. BOURDIEU, Pierre. Espíritos de Estado: gênese e estrutura do campo burocrático. In: BOURDIEU, Pierre. Razões práticas: sobre a teoria da ação. Campinas: Papirus, 1996. p. 91-123.

5. BRITO, Angela Xavier de. Habitus de migrante: um conceito que visa captar o cotidiano dos atores em mobilidade espacial. In: Sociedade e Estado, v. 25, n. 3, set-dez 2010, p. 431-464.

6. CHICHA, Marie-Thérèse; CHAREST, Éric. L'intégration des immigrés sur le marché du travail à Montréal : politiques et enjeux. In : Choix. Institut de recherche en politiques publiques, Montréal, v. 14, n. 2, mar. 2008, p. 1-62.

7. FONTAINE, Louise. Immigration and cultural policies: a bone of contention between the province of Quebec and the Canadian Federal Government. In: International Migration Review, vol. 29, issue 3, New York, Winter 1995.

8. FONTAINE, Louise. Un labyrinthe carré comme un cercle. Enquête sur le Ministère des Communautés Culturels et de l'Immigration et ses acteurs réels et imaginés. Montréal: Les Editions Etincelle, 1993.

9. FREITAS, Maria Ester de. A mobilidade como novo capital simbólico nas organizações ou sejamos nômades? In: Organizações e Sociedade, Salvador, v. 16, n. 49, abr.-jun. 2009, p. 247-264. 
10. HOULE, François. Citoyenneté, espace public et multiculturalisme: la politique canadienne de multiculturalisme. In : Sociologie et sociétés, vol. 31, n. 2, 1999, p. 101-123.

11. LABELLE, Micheline ; ROCHER, François ; ROCHER, Guy. Pluriethnicité, citoyenneté et intégration : de la souveraineté pour lever les obstacles et les ambiguïtés. In : Cahiers de recherche sociologique, n. 25, 1995, p. 6-43.

12. LATOUCHE, Daniel. Immigration, politique et société: le cas du Québec. In: QUÉBEC. Séminaire Scientifique sur les tendances migratoires actuelles et I'insertion des migrants dans les pays de la francophonie. Québec: Les Publications du Québec, 1989, p. 179-196.

13. LINTEAU, Paul-André. Les grandes tendances de l'immigration au Québec (1945-2005). In : Migrance, n. 34, jul. 2009, p. 30-41.

14. MINISTERES DES COMMUNAUTES CULTURELLES ET DE L'IMMIGRATION DU QUEBEC (MCCl). Autant de façons d'être Québécois. Plan d'action du gouvernement du Québec à l'intention des communautés culturelles. Québec: Développement culturel et scientifique, 1981.

15. MINISTERES DES COMMUNAUTES CULTURELLES ET DE L'IMMIGRATION DU QUEBEC (MCCI). Direction de Communication. Au Québec pour bâtir ensemble. Énoncé de Politique en Matiére d’Immigration et d'Intégration. Montréal: Publications Daz Inc., 1991.

16. MINISTÈRE DE L'IMMIGRATION ET DES COMMUNAUTES CULTURELLES DU QUÉBEC (MICC). Plan d'immigration du Québec pour l'année 2008. Québec, 2007. Disponível em: <http://www.micc.gouv.qc.ca/publications/fr/planification/Plan-immigration-2008.pdf>. Acesso em: 20 abr. 2010.

17. MINISTÈRE DE L'IMMIGRATION ET DES COMMUNAUTES CULTURELLES DU QUÉBEC (MICC). Pour enrichir le Québec: mesures pour renforcer I'action du Québec en matière de francisation des immigrants (Franciser plus, intégrer mieux). Québec, 2008a. Disponível em <http://www.micc.gouv.qc.ca/publications/fr/ mesures/Mesures-Francisation-Brouchure2008.pdf>. Acesso em: 22 mar. 2010.

18. MINISTÈRE DE L'IMMIGRATION ET DES COMMUNAUTES CULTURELLES DU QUÉBEC (MICC). Pour enrichir le Québec: affirmer les valeurs communes de la société québequoise (Franciser plus, intégrer mieux). Quebec, 2008b. Disponível em <http://www.micc.gouv.qc.ca/publications/fr/mesures/Mesures-ValeursCommunes-Brouchure2008.pdf>. Acesso em: 22 mar. 2010.

19. MINISTÈRE DE L'IMMIGRATION ET DES COMMUNAUTES CULTURELLES DU QUÉBEC (MICC). Pour enrichir le Québec: mesures pour renforcer I'action du Québec en matière d'intégration en emploi des immigrants (Franciser plus, intégrer mieux). Québec, 2008c. Disponível em: http://www.micc.gouv.qc.ca/publications/ fr/mesures/Mesures-Integration-Brouchure2008.pdf Acesso em: 22 mar. 2010. 
Sociologias, Porto Alegre, ano 17, no 39, mai/ago 2015, p. 248-275

20. MINISTÈRE DE L'IMMIGRATION ET DES COMMUNAUTES CULTURELLES DU QUÉBEC (MICC). Le succès par le français: à vous d'agir! Québec, 2009. Disponível em: <http://www.immigration-quebec.gouv.qc.ca/publications/fr/ langue-francaise/succes-parle-francais.pdf>. Acesso em: 15 jun. 2010.

21. MINISTÈRE DE L'IMMIGRATION ET DES COMMUNAUTES CULTURELLES DU QUÉBEC (MICC). Tableaux sur I'immigration permanente au Québec : 2007-2011. Québec, 2012. Disponível em : http://www.bdso.gouv.qc.ca/docsken/multimedia/PB1200FR_Immigration2011.pdf. Acesso em: 23 maio 2012.

22. MICC. Présence en 2012 des immigrants admis au Québec de 2001 à 2010. Québec. 2013. Disponível em: http://www.micc.gouv.qc.ca/publications/fr/ recherches-statistiques/Presence 2012 immigrants admis Qc 2001-2010.pdf. Acesso em: 14 abr. 2014.

23. MINISTÈRE DES RELATIONS INTERNATIONALES DU QUÉBEC (MRI). Le Québec inaugure sa représentation au Brésil. Québec, 2010. Disponível em: http://www.mri.gouv.qc.ca/fr/_scripts/actualites/ViewNew. asp?NewID=7118\&Menu=\&lang=fr. Acesso em: 12 mar. 2011.

24. MINISTÈre DES RELATIONS INTERNATIONALES DU QUÉBEC (MRI). Principaux secteurs de collaboration: immigration. Québec, 2012. Disponível em: http://www.mri.gouv.qc.ca/fr/relations_quebec/ameriques/amerique_du_sud/bresil/resume.asp\#Immigration. Acesso em: 12 mar. 2011.

25. NOIRIEL, Gérard. État, nation et immigration. Paris : Belin, 2001.

26. PELLETIER, Réjean. La Révolution Tranquille. Les classiques des sciences sociales. Disponível em: http://www.uqac.uquebec.ca/zone30/Classiques_des_sciences_sociales/index.html. Acesso em: 23 dez. 2010.

27. STATISTICS CANADA. Projections de la population des groupes de minorités visibles: Canada, provinces et régions - 2001-2017. Ottawa: Statistics Canada, 2008.

28. STATISTICS CANADA. Immigration and Citizenship Highlight Tables 2006 Census. Disponível em: http://www12.statcan.gc.ca/census-recensement/2006/ rt-td/immcit-fra.cfm $=0 \& V N A M E E=\& V N A M E F=\#$ archived. Acesso em: 14/04/2014.

29. SASSEN, Saskia. Sociologia da Globalização. Porto Alegre: Artmed, 2010.

30. THE ATLAS OF CANADA. Political divisions. Disponível em http://atlas. nrcan.gc.ca/site/english/maps/reference/national/can_political_e/. Acesso em: 13 mar. 2011.

Recebido em: 21/01/2015

Aceite Final: 19/03/2015 